\title{
Determinants of lungworm specificity in five cetacean species in the western Mediterranean
}

\author{
Rachel Pool ${ }^{*}$ D, Clara Romero-Rubira, Juan Antonio Raga, Mercedes Fernández and Francisco Javier Aznar
}

\begin{abstract}
Background: Current data about Pseudaliidae show contrasting patterns of host specificity between congeneric species. We investigated how both contact and compatibility between hosts and parasites contributed to the patterns of lungworm infection observed in a community of five species of cetaceans in the western Mediterranean.

Methods: The lungs of 119 striped dolphins Stenella coeruleoalba, 18 bottlenose dolphins Tursiops truncatus, 7 Risso's dolphins Grampus griseus, 7 long-finned pilot whales Globicephala melas, and 6 common dolphins Delphinus delphis were analysed for lungworms. Parasites were identified by morphology and analysis of ITS2 sequences using both maximum likelihood and Bayesian inference methods. Body length was used as a proxy for lungworm species fitness in different hosts and compared with Kruskal-Wallis tests. Infection parameters were compared between cetacean species using Fisher's exact tests and Kruskal-Wallis tests. Phylogenetic specificity was explored by collating the overall lungworm species prevalence values in hosts from previous surveys in various localities. To explore the relative importance of vertical and horizontal transmission, Spearman's rank correlation was used to look for an association between host size and lungworm burden. A Mantel test was used to explore the association between lungworm species similarity and prey overlap using dietary data.
\end{abstract}

Results: Halocercus delphini had higher infection levels in striped dolphins and common dolphins; Stenurus ovatus had higher infection levels in bottlenose dolphins; and Stenurus globicephalae had higher infection levels in longfinned pilot whales. These results are congruent with findings on a global scale. Morphometric comparison showed that the larger nematodes were found in the same host species that had the highest parasite burden. Lungworms were found in neonatal striped dolphins and a Risso's dolphin, and there was a weak but significant correlation between host size and parasite burden in striped dolphins and bottlenose dolphins. There was also a weak but significant association between prey overlap and lungworm species similarity.

Conclusions: Data indicate that phylogenetic specificity has an important role in governing host-parasite associations, as indicated by the higher infection levels and larger nematode size in certain hosts. However, diet can also influence infection patterns in these preferred hosts and contribute to less severe infections in other hosts.

Keywords: Lungworms, Pseudaliidae, Cetaceans, Mediterranean Sea, Host specificity, Parasites

*Correspondence: Rachel.Pool@uv.es

Marine Zoology Unit, Cavanilles Institute of Biodiversity and Evolutionary Biology, Science Park, University of Valencia, PO Box 22085,

Valencia 46071, Spain

\section{Background}

Adults of all but one of the 29 currently valid species of lungworms of the family Pseudaliidae typically infect the lungs, middle ear and air sinuses of odontocetes worldwide $[1,2]$. In heavy infections, lungworms can cause severe health problems such as osseous lesions in the cranial sinuses, blocked airways, verminous pneumonia and 
secondary bacterial infections, all of which can lead to the stranding or even death of their hosts [1].

Little is known about the life cycles of pseudaliids. Other metastrongyloid nematodes infecting terrestrial or marine mammals have heteroxenous cycles and, depending on the habitat, can use gastropods or oligochaetes as intermediate hosts, or fish as paratenic hosts $[1,3]$. In pseudaliids, however, direct evidence on the use of intermediate or paratenic hosts is limited to a single species. Lehnert et al. [4] detected larvae of Pseudalius inflexus in dabs Limanda limanda, which are common prey of harbour porpoises Phocoena phocoena (definitive hosts) in North Sea waters. In other pseudaliids, evidence for trophic transmission is only implied by the absence of infection in unweaned hosts, coupled with the increase in prevalence with host age [1]. However, there is also evidence for vertical transmission from mother to calf at least for three species of Halocercus infecting bottlenose dolphins Tursiops truncatus, orcas Orcinus orca, and striped dolphins Stenella coeruleoalba [5-7].

Data about the specificity of pseudaliids are similarly scarce, in part because host sampling is problematic and experimental work virtually impossible. Based on hostparasite records, it would seem that patterns of specificity are contrasting even between congeneric species. For example, Stenurus minor seems to be widespread among members of the families Phocoenidae, Delphinapteridae and Delphinidae, whereas Stenurus arctomarinus has only been reported in the beluga whale Delphinapterus leucas $[2,8]$. In addition, the same odontocete species can have strikingly different levels of infection for the same pseudaliid species depending on geographic location. For example, the prevalence of Halocercus lagenorhynchi in striped dolphins in Italy, the UK and Costa Rica was $6.67 \%, 14.3 \%$ and $54.2 \%$, respectively [9-11], and this species has never been detected in striped dolphins from the western Mediterranean Sea despite the high sampling effort [7].

Generally speaking, patterns of specificity can be understood as the result of two sequential filters, i.e., contact and compatibility [12-14], which operate at the local community of relevant hosts. Investigating the action of these filters obviously requires data on life cycles (to shed light on patterns of contact) and data on fitness in each host (to shed light on patterns of compatibility). Furthermore, the analysis of specificity must be addressed considering different facets [15], i.e., (1) structural specificity (how parasite populations are distributed among the host species of the local community), (2) phylogenetic specificity (the extent to which these hosts are historically related), and (3) specificity in geographic space (how consistent host use is across a changing host geographic landscape). And, above all, any specificity analysis obviously assumes that parasites are reliably identified.

In this study we investigate, for the first time, patterns of host specificity of the Pseudaliidae in a local community of five cetacean species following the above scheme. First, we combined morphological and molecular methods to verify whether putative nematode species infecting different hosts are indeed conspecific. Second, we looked for evidence of vertical and/or trophic transmission for each lungworm species. Since direct detection of intermediate or paratenic hosts has proven unsuccessful to date (see, e.g., [16]), we investigated the probability of parasite exchange among host species through dietary overlap analysis, assuming that the greater the overlap in the consumption of infected prey species, the higher the probability that the hosts share the same parasites [12-14]. Third, we used proxies to compare fitness of lungworms between host species. Finally, we explored the consistency of host choice in other cetacean communities and estimated the global phylogenetic specificity of the lungworm species based on overall records.

\section{Methods \\ Sample collection}

Pseudaliid lungworms were collected from the carcasses of 119 striped dolphins Stenella coeruleoalba, 18 bottlenose dolphins Tursiops truncatus, 7 Risso's dolphins Grampus griseus, 7 long-finned pilot whales Globicephala melas, and 6 short-beaked common dolphins Delphinus delphis that were found stranded along the Mediterranean coast of Spain (Valencian Community, between $40^{\circ} 31^{\prime} 00^{\prime \prime} \mathrm{N}, 0^{\circ} 31^{\prime} 00^{\prime \prime} \mathrm{E}$ and $37^{\circ} 50^{\prime} 00^{\prime \prime} \mathrm{N}$, $\left.0^{\circ} 45^{\prime} 42^{\prime \prime} \mathrm{W}\right)$ between 1982 and 2019. In the case of the striped dolphins, we excluded individuals from 1990 and 2007 because they had suffered a Morbillivirus outbreak, which could produce a confounding effect on parasite abundance. Only carcasses in preserved states 1-3 [17] were selected for analysis.

During the necropsy, the animals were measured and sexed; their cranium was disarticulated from the spine and cranial sinuses were examined for parasites, and the lungs were removed and stored at $-20{ }^{\circ} \mathrm{C}$. Only one lung per individual, randomly selected, was used in this study; the other was saved for a future study on microhabitat selection. After thawing, the airways of each lung were cut from the trachea to the caudal apex and rinsed over a $0.2 \mathrm{~mm}$ sieve.

All fragments and whole worms were collected, cleaned in $0.9 \%$ saline, and fixed and preserved in $70 \%$ or $90 \%$ ethanol for morphological and molecular analysis, respectively. Specimens were examined under a light microscope and identified following Delyamure [18]. Due 
to the tendency of some lungworm species to embed their anterior ends in the parenchyma, it was difficult to extract worms whole. Thus, the total worm number per lung was estimated as the number of complete worms, or incomplete worms with their caudal end intact. In the case of pilot whales, only presence/absence data for lungworm species could be recorded.

\section{Molecular identification of species}

Extraction of genomic DNA using the DNeasy ${ }^{\circledR}$ Blood and Tissue Kit (QIAGEN, Hilden, Germany) was successful for 21 out of 26 selected lungworms from 12 hosts (Table 1). The second internal transcribed spacer (ITS2) of nuclear ribosomal DNA was chosen as the barcoding genetic marker due to its reliability in nematode species identification $[4,19]$. The primers PseuITS2F $\left(5^{\prime}\right.$-CCT TCG GCA CAT CTT GTT CA-3') and PseuITS2R (5'GGG TAA TCA CAT CTG AGT TCA-3') [19] were used at a concentration of $5 \mathrm{pmol} / \mu \mathrm{l}$. The polymerase chain reaction (PCR) reaction mixtures had a final volume of $20 \mu \mathrm{l}$, with $2 \mu \mathrm{l}$ DNA, $4.8 \mu \mathrm{l}$ PCR water, $1.6 \mu \mathrm{l}$ of each primer and $10 \mu \mathrm{l}$ MyFiTM DNA Polymerase (Bioline, Meridian Life Science, Inc., Taunton, MA, USA). After an initial heat-activation step of $94{ }^{\circ} \mathrm{C}$ for $3 \mathrm{~min}$, the reaction consisted of 39 cycles of $94{ }^{\circ} \mathrm{C}$ for $1 \mathrm{~min}, 58^{\circ} \mathrm{C}$ for $1 \mathrm{~min}$ and $72{ }^{\circ} \mathrm{C}$ for $1 \mathrm{~min}$, followed by a final step at $72{ }^{\circ} \mathrm{C}$ for 5 min. Positive and negative (no DNA) controls were used in each PCR.

Table 1 GenBank accession numbers of sequences of second internal transcribed spacer (ITS2) used in the phylogenetic analyses of 20 individuals of three species of the family Pseudaliidae Railliet and Henry 1909

\begin{tabular}{|c|c|c|c|c|c|}
\hline GenBank Acc. no. & Sequence ID & Seq. length (bp) & Family & Host $^{a}$ & Locality \\
\hline DQ408626 & Heligmosomum mixtum & & Heligmosomidae & $\mathrm{Cg}$ & Poland \\
\hline DQ679968 & Hovorkonema variegatum & & Syngamidae & Ggu & Germany \\
\hline AY491979 & Otostrongylus circumlitus & & Crenosomatidae & $P \vee$ & NE Atlantic \\
\hline FJ787304 & Parafilaroides gymnurus & & Filaroididae & $P \vee$ & NE Atlantic \\
\hline FJ787301 & Halocercus invaginatus & & Pseudaliidae & $\mathrm{Pp}$ & NE Atlantic \\
\hline FJ767935 & Pseudalius inflexus & & Pseudaliidae & $\mathrm{Pp}$ & NE Atlantic \\
\hline AY464532 & Torynurus convolutus & & Pseudaliidae & $\mathrm{Pp}$ & NE Atlantic \\
\hline FJ787302 & Stenurus minor & & Pseudaliidae & $\mathrm{Pp}$ & NE Atlantic \\
\hline FJ787303 & Stenurus globicephalae & & Pseudaliidae & Gm & NE Atlantic \\
\hline MW192227 & Stenurus globicephalae Gm1-1 & 496 & Pseudaliidae & Gm & Mediterranean \\
\hline MW192228 & Stenurus globicephalae Gm1-2 & 507 & Pseudaliidae & Gm & Mediterranean \\
\hline MW192226 & Stenurus globicephalae Gg & 530 & Pseudaliidae & $\mathrm{Gg}$ & Mediterranean \\
\hline MW192229 & Stenurus ovatus Sc & 530 & Pseudaliidae & Sc & Mediterranean \\
\hline MW192230 & Stenurus ovatus Tt1-1 & 517 & Pseudaliidae & $\mathrm{Tt}$ & Mediterranean \\
\hline MW192231 & Stenurus ovatus Tt1-2 & 513 & Pseudaliidae & $\mathrm{Tt}$ & Mediterranean \\
\hline MW192225 & Halocercus delphini Gg & 513 & Pseudaliidae & $\mathrm{Gg}$ & Mediterranean \\
\hline MW192224 & Halocercus delphini Tt & 525 & Pseudaliidae & $\mathrm{Tt}$ & Mediterranean \\
\hline MN747504 & Halocercus delphini Dd1-1 & 523 & Pseudaliidae & $\mathrm{Dd}$ & NE Atlantic \\
\hline \multirow[t]{4}{*}{ MN747503 } & Halocercus delphini Dd2-1 & 487 & Pseudaliidae & $\mathrm{Dd}$ & Mediterranean \\
\hline & Halocercus delphini Sc1-1 & 479 & Pseudaliidae & Sc & Mediterranean \\
\hline & Halocercus delphini Sc2-1 & 472 & Pseudaliidae & Sc & Mediterranean \\
\hline & Halocercus delphini Sc3-1 & 437 & Pseudaliidae & Sc & Mediterranean \\
\hline \multirow[t]{7}{*}{ MN747502 } & Halocercus delphini Sc3-2 & 555 & Pseudaliidae & Sc & Mediterranean \\
\hline & Halocercus delphini Sc3-3 & 521 & Pseudaliidae & Sc & Mediterranean \\
\hline & Halocercus delphini Sc3-4 & 385 & Pseudaliidae & Sc & Mediterranean \\
\hline & Halocercus delphini Sc4-1 & 413 & Pseudaliidae & Sc & Mediterranean \\
\hline & Halocercus delphini Sc4-2 & 540 & Pseudaliidae & Sc & Mediterranean \\
\hline & Halocercus delphini Sc4-3 & 449 & Pseudaliidae & Sc & Mediterranean \\
\hline & Halocercus delphini Sc4-4 & 536 & Pseudaliidae & Sc & Mediterranean \\
\hline
\end{tabular}

Heligmosomum mixtum Schulz, 1929, Hovorkonema variegatum Creplin, 1849, Otostrongylus circumlitus Railliet, 1899, and Parafilaroides gymnurus Railliet, 1899, were used as outgroups. In samples of Stenurus globicephalae, Stenurus ovatus, and Halocercus delphini, ID numbers stand for individual host and individual specimen, respectively

a Host codes: Cg: Clethrionomys glareolus Schreber; Ggu: Grus grus Linnaeus; Pv: Phoca vitulina Linnaeus; Pp: Phocoena phocoena Linnaeus; Gm: Globicephala melas Traill; Gg: Grampus griseus Cuvier; Sc: Stenella coeruleoalba Meyen; Dd: Delphinus delphis Linnaeus 
Aliquots of $2 \mu \mathrm{l}$ of each amplicon were mixed with $2 \mu \mathrm{l}$ of loading dye and run on agarose gel (1\% gel of $0.4 \mathrm{~g}$ agar powder and $40 \mathrm{ml}$ TE buffer) stained with GelRed ${ }^{\circledR}$ Nucleic Acid Gel Stain (Biotium, Hayward, CA, USA) for electrophoresis. The bands were visualized and photographed using an ultraviolet light hood. After purification with the Nucleospin ${ }^{\circledR}$ PCR and Gel Purification Clean-up kit (Machery-Nagel, Düren, Germany), amplicons were sent to Macrogen Europe (Amsterdam, Netherlands) for sequencing with the same primers used for the PCR reactions.

Nucleotide sequences from both strands were used to assemble consensus sequences with Geneious R7 (https://www.geneious.com). The sequences of $\mathrm{H}$. delphini from $D$. delphis and $S$. coeruleoalba were previously published in Pool et al. [20].

Sequences were aligned using MAFFT [21] with published GenBank sequences for the Pseudaliidae, with Heligmosomum mixtum Schulz, 1929, and Hovorkonema variegatum Creplin, 1849, being designated as outgroups (see [20], Table 1). The resulting alignment was edited to cut significant gaps using the heuristic method in trimAl v1.2 [22] and then analysed using maximum likelihood (ML) and Bayesian inference (BI) methods. Both methods used the Hasegawa-Kishino-Yano nucleotide substitution model with a gamma rate of inversion, which was selected according to the Akaike information criterion (AIC) by jModelTest [23, 24]. The ML analysis was conducted in MEGA X [25] with 500 bootstrap replications. The BI analysis was performed with MrBayes 3.2.5 [26], with posterior probability values calculated by four simultaneously running Markov chains using 1,200,000 generations. Trees were sampled every 1000th generation, and an average standard deviation of split frequencies $<0.01$ was used as an indication that convergence had been achieved. A total of $25 \%$ of the trees were discarded as burn-in.

Tree topologies of the ML and BI analyses were checked for congruence using the FigTree v.1.4.4 program [27]. Pairwise distances were also calculated with MEGA X [24], with complete deletion of gaps.

\section{Specificity analysis}

We set the 95\% confidence interval for prevalence of lungworms using Sterne's exact method and, for mean intensity and mean abundance, the bias-corrected and accelerated bootstrap method with 20,000 replications [28]. Prevalence and intensity of lungworm species were compared between host species with Fisher's exact and Kruskal-Wallis tests, respectively. In pairwise comparisons, $P$ values were corrected by the Holm-Bonferroni sequential method with $\alpha=0.05$. Note, however, that the power of some tests was low due to small host sample sizes.

To investigate the life cycles of lungworms, dolphins of each species were separated into three age categories, i.e. neonate, suckling and weaned individual, based on published data (Table 2). Then, for each lungworm species, the possibility of vertical and/or horizontal transmission was explored by recording infection in neonates (suggestive of vertical transmission) and/or weaned individuals (suggestive of horizontal transmission), respectively. When sample size allowed, we also used one-tailed Spearman correlation to test for an increase in worm abundance with host body length (excluding neonates), since larger hosts could have more infection opportunities due to higher food consumption [1].

The influence of trophic transmission on patterns of infection was further explored by examining whether there was a significant association between diet and lungworm fauna among host species. Dietary data were available from the very same samples of dolphins used for the present parasitological analysis [34], [35], [36], unpublished data], except long-finned pilot whales, for which we chose data from the nearest geographical region, the Iberian Atlantic [37]. We did not expect fundamental differences in diet between the Atlantic and Mediterranean populations of pilot whales because prey data were dealt with at the genus level. For each dolphin species, we selected all prey taxa that had been identified at least up to genus level (in all dolphin species, they represented $\geq 90 \%$ of total individual prey), and obtained the matrix of pairwise percent similarity index (PS) of diet between dolphin species:

$$
\mathrm{PS}_{i j}=\Sigma_{k} \min \left(y_{k i}, y_{k j}\right) /\left(\Sigma_{k} y_{k i+} \Sigma_{k} y_{k j}\right),
$$

where $\min \left(y_{k i}, y_{k j}\right)$ is the minimum value of frequency of occurrence (\%) in each pair of shared prey between dolphin species $i$ and $j$ summed across $k$ shared species, and $\left(\Sigma_{\mathrm{k}} y_{k i+} \Sigma_{k} y_{k j}\right)$ is the sum of the frequency of occurrences of all prey in both dolphin species. Likewise, we obtained the PS matrix for lungworm fauna based on prevalence data. The potential association between the prey and lungworm matrices was tested with the Mantel test [38].

We used adult female worm size to examine the potential effects of each dolphin species on the fitness of each lungworm species [39] (i.e., the compatibility filter). We collected as many intact adult female worms as possible up to 10 individuals per lungworm and dolphin species. Unfortunately, sample sizes were smaller in some cases because not enough (suitable) specimens were found. The selected females were put on a Petri dish with saline and covered with a microscope slide; their length was measured from drawings obtained with the aid of a drawing 
Table 2 Age groups of each cetacean host species based on body lengths from previously published literature

\begin{tabular}{|c|c|c|c|c|c|}
\hline \multirow[t]{2}{*}{ Host species } & \multicolumn{3}{|c|}{ Body length $(\mathrm{cm})$} & \multirow[t]{2}{*}{ Locality } & \multirow[t]{2}{*}{ References } \\
\hline & Neonate & Suckling & Weaned & & \\
\hline Stenella coeruleoalba & $<93$ & $93-165$ & $\geq 165$ & Mediterranean Sea & Pool et al. [7] \\
\hline \multicolumn{6}{|l|}{ Striped dolphin } \\
\hline Tursiops truncatus & $<115$ & $115-170$ & $\geq 170$ & NW Atlantic Ocean & Read et al. [29] \\
\hline Bottlenose dolphin & & & & & Struntz et al. [30] \\
\hline Grampus griseus & $<140$ & $140-230$ & $\geq 230$ & Mediterranean Sea & Raduan et al. [31] \\
\hline Risso's dolphin & & & & NW Atlantic Ocean & Bloch et al. [32] \\
\hline Delphinus delphis & $<93$ & $93-160$ & $\geq 160$ & Atlantic Ocean & Westgate and \\
\hline Common dolphin & & & & & Read [33] \\
\hline
\end{tabular}

tube connected to a stereomicroscope $(\times 100)$. Depending on the lungworm species and number of available specimens, worm length was compared with one-way analysis of variance (ANOVA) with post hoc Šidák test, $t$ test for independent samples or one-sample $t$ tests (see the "Results" Section).

To explore phylogenetic specificity, we searched available parasitological surveys in the bibliography that recorded any of the lungworms specie found in the present study. Then, we obtained overall values of prevalence per host species (i.e., total number of infected hosts / total host sample size, regardless of locality). To control for sampling effort, these prevalence values were weighed by relative sample size of each host species. Weighed values were placed in the most recent phylogenetic tree of the order Cetacea [40] and interpreted visually. On the other hand, the geographical consistency in host use was examined based on all parasitological surveys of local cetacean communities in which (1) at least one of the lungworm species detected in this study was reported, and (2) at least three host species of different genera were analysed for lungworms.

Quantitative Parasitology version 3.0 software was used to calculate parasite burden parameters [41]. The Mantel test was carried out with the free software PASSaGE version 2 [38]. All other statistical analyses were performed with R [42]. The significance level was set at $P<0.05$.

\section{Results}

A total of 3 of 7 long-finned pilot whales, 4 of 7 Risso's dolphins, 9 of 18 bottlenose dolphins, all 6 common dolphins, and 73 of 119 striped dolphins were infected with lungworms. Three species of lungworm were morphologically identified in the whole sample of hosts, namely, Halocercus delphini, Stenurus ovatus and S. globicephalae (Table 3).

\section{Molecular analysis}

Contigs of the ITS2 region were able to be obtained from 21 lungworms. After trimming, the alignment was $303 \mathrm{bp}$ long; 8 sequences were uploaded to GenBank (Table 1). We obtained three partial ITS2 sequences of Stenurus ovatus (513-550 bp long), one from a striped dolphin and two from a bottlenose dolphin. Comparison of pairwise divergence in the alignment showed that all three sequences were identical.

Four partial ITS2 sequences of Stenurus globicephalae were obtained, one from Risso's dolphin and three from the long-finned pilot whale. One of the longfinned pilot whale sequences was discarded from the alignment because it was too short (248 bp long). The sequence from Risso's dolphin was identical to one of the sequences from the pilot whale; the second pilot whale sequence had a pairwise divergence of 0.012 .

Fourteen partial ITS2 sequences of Halocercus delphini were obtained. Uncorrected pairwise distances in the alignment varied between 0.000 and 0.060 (Additional file 1: Table S1).

The ML and BI analyses produced trees with dissimilar topology regarding the outgroups, but in both trees all samples of Stenurus ovatus appeared as a highly supported clade (ML: 100\%; BI: 1), with Stenurus minor and Torynurus convolutus as the sister taxa (Fig. 1). All samples of Stenurus globicephalae, including the previously published sequence from GenBank, also appeared together in a highly supported clade (ML: 99\%; BI: 1) in both trees (Fig. 1). Halocercus invaginatus appeared as the sister taxon of a highly supported clade in which all of the samples of Halocercus delphini (regardless of host species) clustered together (ML: 99\%; BI: 1) (Fig. 1).

\section{Specificity analysis}

Halocercus delphini was found in the lungs of all host species except pilot whales (Table 3). The prevalence 


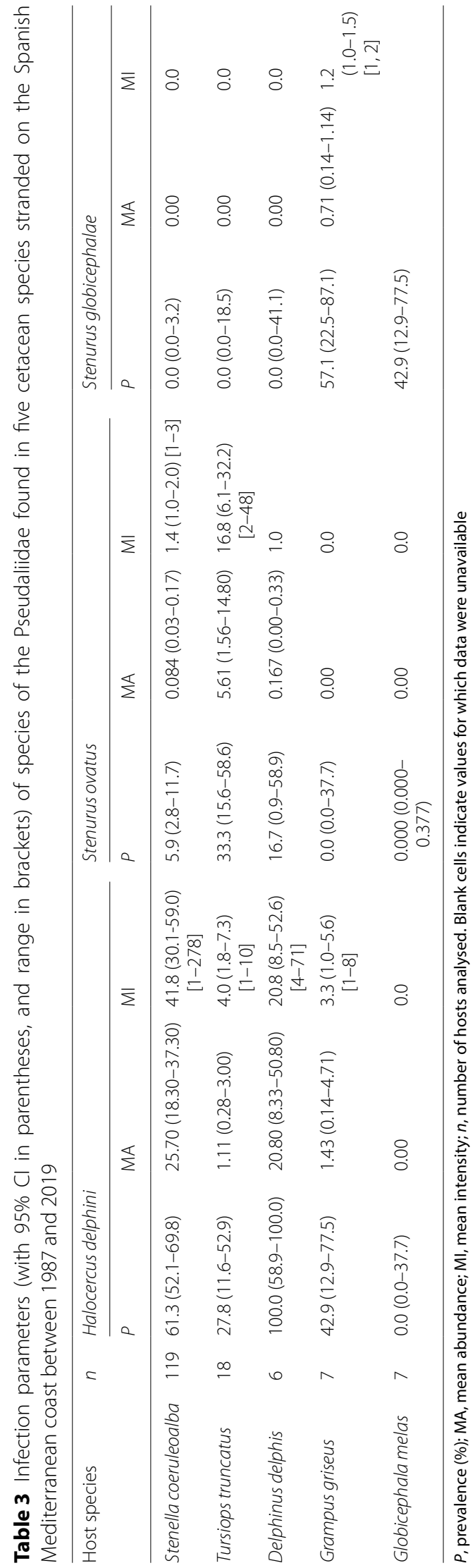


(Fisher's exact test, $P=0.004$ ) differed significantly between host species, being significantly higher in striped and common dolphins compared with bottlenose dolphins and pilot whales. The intensity also differed among infected species (Kruskal-Wallis test, $\chi^{2}=10.37,3$ $d f, P=0.016$ ), with significantly higher values in striped dolphins compared with those from bottlenose and Risso's dolphins (Tables 3,4 ).

Stenurus ovatus was found in the lungs of bottlenose, common and striped dolphins, and both the prevalence $(P=0.004)$ and the intensity $\left(\chi^{2}=8.89,2 d f, P=0.012\right)$ were significantly higher in bottlenose dolphins than striped dolphins (Table 4); a single worm was found in one common dolphin (Table 3, 4). Finally, S. globicephalae was detected in the lungs of Risso's dolphins and the lungs and cranial sinuses of long-finned pilot whales (Table 2). The statistical analysis revealed significant differences in prevalence between these hosts and bottlenose and striped dolphins (Table 4).

Five neonates of striped dolphin harboured $H$. delphini (range of intensity: 1-80), and a single neonate of Risso's dolphin (136 cm long) harboured 8 individuals of $\mathrm{H}$. delphini and 1 of S. globicephalae (Table 5). Lungworms of all species also occurred in both suckling and weaned hosts. The abundance of $H$. delphini was positively, but weakly, associated with host body length in the striped dolphin $\left(r_{\mathrm{s}}=0.152, n=114\right.$, one-tailed $\left.P=0.053\right)$; the association was much stronger in the case of $S$. ovatus in bottlenose dolphins $\left(r_{\mathrm{s}}=0.677, n=18, P=0.001\right)$.

There was non-negligible overlap in the diet of the five cetaceans under study; shared prey included both fish and cephalopods in all cases (Additional file 2: Table S2). The overlap was particularly high between the two predominantly teuthophagous species (pilot whales and Risso's dolphin), the two predominantly piscivorous species (bottlenose dolphin and common dolphin), and the species with a mixed diet (the striped dolphin) with respect to the remaining ones (Table 6). A weak but significant positive association between diet overlap and similarity was detected in the lungworm fauna (Table 6, Mantel test, $r_{\mathrm{M}}=0.57$, one-tailed $P=0.011$ ).
Data on body length of female lungworms were difficult to obtain from some hosts due to very low infection levels and/or scarcity of intact worms. A total of 10 individuals of $H$. delphini could be measured from striped dolphins (mean \pm SD [mm]: $58.9 \pm 14.3$ ), 5 from common dolphins (48.0 \pm 11.1$), 2$ from bottlenose dolphins $(20.1 \pm 3.7)$, and none from Risso's dolphin. Mean length values differed significantly (one-way ANOVA, $F_{(2,11)}=7.48, P=0.009$ ); the probability associated with pairwise comparisons (Šidák test) was $P=0.008$ (striped vs bottlenose dolphins); 0.064 (common vs bottlenose dolphin) and $P=0.378$ (striped vs common dolphin). In the case of $S$. ovatus, 10 females could be measured from bottlenose dolphins (22.9 \pm 4.5$)$, 2 from striped dolphin $(9.2 \pm 11.0)$ and none from common dolphin. Mean length values differed significantly between bottlenose and striped dolphin ( $t$ test, $t=3.20,10$ $d f, P=0.009)$. Finally, the number of measured females of S. globicephalae were 10 from pilot whales $(46.1 \pm 4.7)$ and just 1 from Risso's dolphin (11.4). The latter value was significantly smaller than the length range observed for pilot whales (one-sample $t$ test, $t=23.5,9 d f, P<0.0001$ ).

Data from previous field surveys reporting quantitative data on any of the lungworm species detected in this study are shown in Additional file 3: Table S3; further qualitative records did not increase the number of infected species (data not shown). All records concern the Atlantic [43-49] and Pacific Oceans [50-58] and the Mediterranean Sea $[59,60]$. Halocercus delphini and S. globicephalae were found in 7 species and S. ovatus in 4 (Fig. 2). When placed in a phylogenetic context, both $H$. delphini and $S$. ovatus were observed to be restricted to the clade of the Delphininae, and S. globicephalae to the clade of the Globicephalinae, with the notable exception of the infection of Leucopleurus (Lagenorhynchus) acutus, which is considered a basal taxon in the Delphinidae (Fig. 2). Data on weighed prevalence indicated that, based on available evidence and sampling effort, $H$. delphini is clearly associated with common dolphin, S. ovatus with bottlenose dolphin, and S. globicephalae with long-finned pilot whales and $L$. acutus (Fig. 2).

\footnotetext{
(See figure on next page.)

Fig. 1 a Maximum likelihood analysis of the phylogenetic relationships of various pseudaliid lungworm samples from cetaceans in the western Mediterranean in relation to other members of the Metastrongyloidea superfamily using second internal transcribed spacer sequences. Heligmosomum mixtum from the family Heligmosomatidae and Hovorkonema variegatum from the family Syngamidae were used as the outgroups. Nodal support is indicated by bootstrap values; bootstrap values less than $50 \%$ are not shown. The scale bar indicates the number of nucleotide substitutions per site. $\mathbf{b}$ Bayesian inference analysis (BI) of the phylogenetic relationships of various pseudaliid lungworm samples from cetaceans in the western Mediterranean in relation to other members of the Metastrongyloidea superfamily using second internal transcribed spacer sequences. Heligmosomum mixtum from the family Heligmosomatidae and Hovorkonema variegatum from the family Syngamidae were used as the outgroups. Nodal support is indicated by BI posterior probabilities; posterior probabilities less than 0.7 are not shown. The scale bar indicates the number of nucleotide substitutions per site
} 


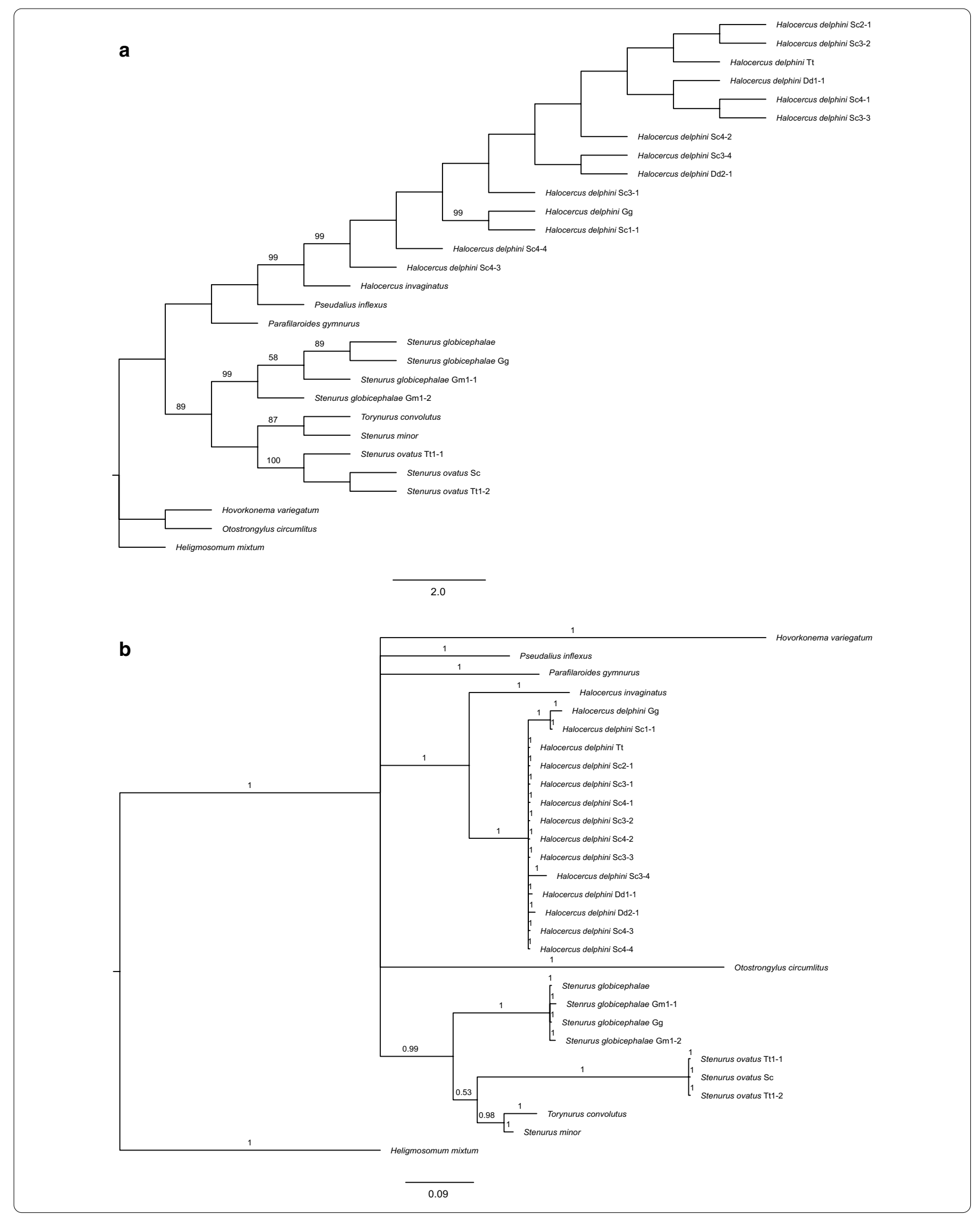


Table 4 Nominal (P) and sequential Bonferroni-corrected (B-P) probability values of pairwise post hoc comparisons of Fisher's test (for prevalence) and Kruskal-Wallis (K-W) test (for intensity) of lungworm species infecting five cetacean species from the western Mediterranean

\begin{tabular}{|c|c|c|c|c|c|c|c|c|c|c|}
\hline \multirow[t]{3}{*}{ Pair } & \multicolumn{4}{|c|}{ Halocercus delphini } & \multicolumn{4}{|c|}{ Stenurus ovatus } & \multirow{2}{*}{\multicolumn{2}{|c|}{$\begin{array}{l}\text { Stenurus globicephalae } \\
\text { Fisher }\end{array}$}} \\
\hline & \multicolumn{2}{|l|}{ Fisher } & \multicolumn{2}{|l|}{ K-W } & \multicolumn{2}{|l|}{ Fisher } & \multicolumn{2}{|l|}{$\mathrm{K}-\mathrm{W}$} & & \\
\hline & $P$ & B-P & $P$ & B-P & $P$ & B-P & $P$ & B-P & $P$ & $B-P$ \\
\hline $\mathrm{Sc}-\mathrm{Tt}$ & $0.010^{*}$ & 0.070 & $0.037^{*}$ & 0.185 & $0.002^{*}$ & $0.022^{*}$ & $0.005^{*}$ & $0.015^{*}$ & 1 & 1 \\
\hline Sc-Dd & 0.084 & 0.422 & 0.754 & 1 & 0.376 & 1 & 0.739 & 0.739 & 1 & 1 \\
\hline Sc-Gg & 0.434 & 0.868 & $0.011^{*}$ & 0.055 & 1 & 1 & & & $<0.0001^{*}$ & $<0.0001^{*}$ \\
\hline Sc-Gm & $0.002^{*}$ & $0.016^{*}$ & & & 1 & 1 & & & $<0.0001^{*}$ & $<0.0001^{*}$ \\
\hline Tt-Dd & $0.003^{*}$ & $0.027^{*}$ & 0.121 & 0.363 & 0.626 & 1 & 0.077 & 0.154 & 1 & 1 \\
\hline $\mathrm{Tt}-\mathrm{Gg}$ & 0.640 & 0.640 & 0.92 & 0.92 & 0.137 & 1 & & & $0.003^{*}$ & $0.022^{*}$ \\
\hline $\mathrm{Tt}-\mathrm{Gm}$ & 0.274 & 0.823 & & & 0.137 & 1 & & & 0.003 & 0.025 \\
\hline $\mathrm{Dd}-\mathrm{Gg}$ & 0.070 & 0.419 & 0.069 & 0.276 & 1 & 1 & & & 0.070 & 0.350 \\
\hline $\mathrm{Dd}-\mathrm{Gm}$ & $0.001^{*}$ & $0.006^{*}$ & & & 1 & 1 & & & 0.070 & 0.350 \\
\hline $\mathrm{Gg}-\mathrm{Gm}$ & 0.193 & 0.772 & & & 1 & 1 & & & 1 & 1 \\
\hline
\end{tabular}

Note that intensity data were not available for one of the two species $(\mathrm{Gm})$ infected with Stenurus globicephalae; thus no intensity comparison was made in this case. Abbreviations: Dd Delphinus delphis; Gg Grampus griseus; Gm Globicephala melas; Sc Stenella coeruleoalba; Tt Tursiops truncatus. *Denotes significance level of $P<0.05$

Table 5 Prevalence $(95 \% \mathrm{Cl})$ of lungworms per age group in five cetacean species from the western Mediterranean

\begin{tabular}{|c|c|c|c|c|c|c|c|}
\hline \multirow[t]{3}{*}{ Parasite } & \multirow[t]{3}{*}{ Host } & \multicolumn{6}{|c|}{ Age group } \\
\hline & & \multicolumn{2}{|c|}{ Neonate } & \multicolumn{2}{|c|}{ Unweaned } & \multicolumn{2}{|c|}{ Weaned } \\
\hline & & $n$ & Prevalence & $n$ & Prevalence & $n$ & Prevalence \\
\hline \multirow{4}{*}{ Halocercus delphini } & Sc & 5 & $20(10.0-65.7)$ & 30 & $63.3(44.9-78.7)$ & 84 & $63.1(52.4-72.8)$ \\
\hline & $\mathrm{Tt}$ & - & - & 2 & 100 & 16 & $18.8(5.2-43.6)$ \\
\hline & $\mathrm{Dd}$ & - & - & 1 & 100 & 5 & $100(50.0-100)$ \\
\hline & $\mathrm{Gg}$ & 1 & 100 & - & - & 6 & $33.3(6.3-72.9)$ \\
\hline \multirow[t]{3}{*}{ Stenurus ovatus } & Sc & - & - & 30 & $3.3(0.2-17.7)$ & 84 & $7.1(3.2-14.7)$ \\
\hline & $\mathrm{Tt}$ & - & - & 2 & 0 & 16 & $37.5(17.8-62.8)$ \\
\hline & $\mathrm{Dd}$ & - & - & 1 & 0 & 5 & $20.0(1.0-65.7)$ \\
\hline \multirow[t]{2}{*}{ Stenurus globicephalae } & $\mathrm{Gg}$ & 1 & 100 & - & - & 6 & $50.0(15.3-84.7)$ \\
\hline & $\mathrm{Gm}$ & 1 & 0 & 1 & 100 & 5 & $40.0(7.7-81.1)$ \\
\hline
\end{tabular}

Cl Confidence Interval

We collected information from six field surveys encompassing $\geq 3$ spp. of delphinids, of which at least one harboured some of the lungworm species detected in this study (Additional file 4: Table S4). Interestingly, in sympatric populations of common dolphins, bottlenose dolphins and Stenella spp., H. delphini did not exhibit a consistent pattern of infection. For instance, in the North Atlantic, this lungworm occurred in common dolphins but not in striped dolphins, whereas in the eastern Pacific it was found in Stenella spp. but not in common dolphins (Additional file 3: Table S3). Although host sample sizes were smaller, S. globicephalae and S. ovatus appeared to be associated with Globicephala spp. and the bottlenose dolphin, respectively (Additional file 3: Table S3).

\section{Discussion}

Using their morphological characteristics, we identified three species of lungworms from the five species of cetaceans examined in this study: Halocercus delphini, Stenurus globicephalae and S. ovatus. The host-parasite associations observed reflect the results of previous parasitological surveys in the area, but this study also provides a new host record for $H$. delphini in Risso's dolphin and a new host record of $S$. ovatus in the short-beaked common dolphin. Only one other lungworm species has been detected in delphinids in the Mediterranean, 
Table 6 Matrices of average percent shared prey taxa (at least at genus level), percent similarity of diet (PSD) and percent similarity of lungworm fauna based on prevalence (PSL) among five odontocete species from the western Mediterranean (see the text for details)

\begin{tabular}{|c|c|c|c|c|}
\hline & $\mathrm{Gm}$ & $\mathrm{Gg}$ & $\mathrm{Tt}$ & $\mathrm{Dd}$ \\
\hline \multicolumn{5}{|c|}{ Percent shared taxa } \\
\hline \multicolumn{5}{|l|}{$\mathrm{Gm}$} \\
\hline $\mathrm{Gg}$ & 38.5 & & & \\
\hline $\mathrm{Tt}$ & 36.5 & 29.7 & & \\
\hline $\mathrm{Dd}$ & 35.1 & 22.3 & 47.1 & \\
\hline Sc & 33.9 & 47.7 & 41.2 & 48.2 \\
\hline \multicolumn{5}{|l|}{ PSD } \\
\hline $\mathrm{Gg}$ & 20.1 & & & \\
\hline $\mathrm{Tt}$ & 12.4 & 11.8 & & \\
\hline $\mathrm{Dd}$ & 13.3 & 10.2 & 18.2 & \\
\hline $\mathrm{Sc}$ & 14.6 & 23.6 & 15.0 & 21.1 \\
\hline \multicolumn{5}{|l|}{ PSL } \\
\hline $\mathrm{Gg}$ & 27.6 & & & \\
\hline $\mathrm{Tt}$ & 0 & 16.9 & & \\
\hline Dd & 0 & 23.5 & 18.2 & \\
\hline $\mathrm{SC}$ & 0 & 28.7 & 27.0 & 35.4 \\
\hline
\end{tabular}

Stenurus minor, which was apparently found in the stomachs of striped dolphins from the Eastern Mediterranean, perhaps as the result of accidental swallowing [66]. These patterns strongly suggest that we likely detected all the lungworm species infecting delphinids in the western Mediterranean.

Although there was an apparent effect of host species on the morphometrics of the worms (see worm size below), the results of the molecular analysis of the ITS2 barcoding region of ribosomal DNA was congruent with species identification based on morphological descriptions. All specimens of each morphospecies clustered together, with high support, and sequences were either identical or showed high levels of similarity, regardless of the host species in which worms were found. Most importantly, the intraspecific variations in pairwise distance were similar to those obtained for other metastrongyloids [67] and did not follow a pattern determined by host species and/or host specimen. Admittedly, the placement of the outgroups varied between ML and BI trees, and in both analyses, Parafilaroides gymnurus was placed firmly within the Pseudaliidae and Torynurus convolutus was the closest relative to Stenurus minor and placed in the Stenurus clade. These phylogenetic incongruences in the Pseudaliidae have previously been noted $[4,68]$, but we think that these taxonomic issues would have a negligible effect on species-level differences.

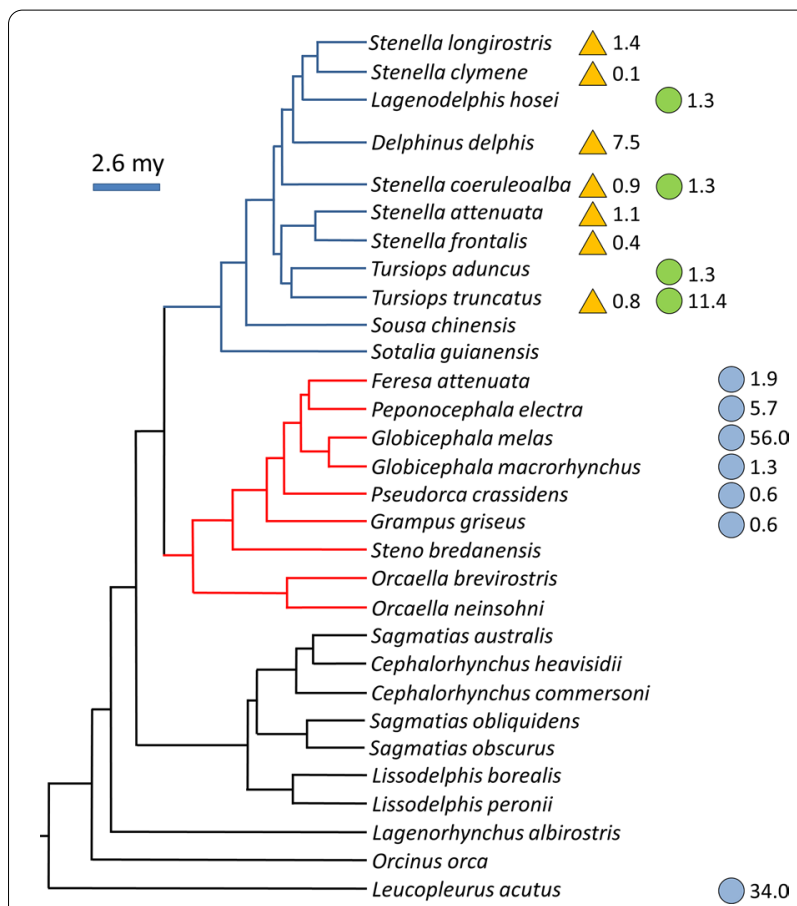

Fig. 2 Weighed prevalence values obtained from surveys conducted in different localities $[10,61-65]$ of the three lungworm species found in this study placed on the phylogenetic tree of the order Cetacea [40]. Abbreviation: my, millions of years ago. Key: $\triangle$, Halocercus delphini; $\bigcirc$, Stenurus ovatus; $\bigcirc$, Stenurus globicephalae

Each parasite was found in multiple hosts, and yet despite small sample sizes and reduced power of statistical tests, each lungworm species showed a tendency to concentrate in one or more host species in particular. Halocercus delphini was found in all hosts except the long-finned pilot whale, but the abundance and prevalence of this parasite were significantly higher in striped dolphins and common dolphins, demonstrating a clear host preference. By contrast, species of Stenurus seemed more host-specific in this study. In the case of $S$. ovatus, which was found in only three of the four cetacean species examined, the main definitive host appears to be the bottlenose dolphin, which, despite its small sample size, had a significantly higher prevalence and abundance of $S$. ovatus than the striped dolphin. Stenurus globicephalae appeared to be the most specific of the lungworms found in this study, having been detected in only the Risso's dolphin and the long-finned pilot whale, with a significantly higher prevalence in the latter.

These results are congruent with the findings of the comparative morphometric analysis of female nematodes, despite the admittedly small sample sizes for some comparisons meaning that the statistical tests lacked substantial power. Females of Halocercus delphini were 
significantly longer in the striped dolphin and the common dolphin, whereas those of $S$. ovatus were longer in the bottlenose dolphin, and females of S. globicephalae were longer in the long-finned pilot whale. Nematode body length is correlated with fecundity [39], and therefore a conservative interpretation would be that there is a correlation between nematode fitness (and therefore host-parasite compatibility) and infection burden.

When the observed parasitic burden patterns are analysed within a wider phylogenetic and geographic context using previous data, we can readily interpret them assuming the operation of phylogenetic specificity. Halocercus delphini was associated with host species from the clade Delphinus + Stenella + Tursiops. Interestingly, the highest overall prevalence value was found in common dolphin, such as we observed in our area. However, the importance of species of Delphinus and Stenella in supporting populations of this parasite seems to vary among localities, with bottlenose dolphin playing a secondary role, if at all (Additional file 4: Table S4). In contrast, bottlenose dolphins appeared to be most associated with $S$. ovatus within the same Delphinus + Stenella + Tursiops clade. On the other hand, S. globicephalae was geographically widespread only in species of the Globicephalinae and the Atlantic white-sided dolphin, Leucopleurus acutus, being most frequently found in long-finned pilot whales.

The consistency of these findings with ours suggests that the infection patterns observed in this study are regulated by host-parasite compatibility, as the parasites may have limited ability to establish themselves in unsuitable hosts. However, the infections of lungworm species outside of their preferred subset of hosts (as observed in this study) are likely driven by contact through shared diet, as supported by the weak but significant positive association between host diet overlap and similarity in the lungworm fauna. Additionally, the significant positive correlations of lungworm abundance with host size in the case of H. delphini in striped dolphins and S. ovatus in bottlenose dolphins show that trophic transmission can also influence lungworm infection patterns within their preferred hosts. It is unlikely that these correlations are the result of long-lasting infections acquired as neonates, as there were no infected neonates of bottlenose dolphins, but also because the prevalence of infection in both species of lungworms was higher in weaned individuals, many of which were adults. Older (larger) dolphins would have had more time to have been exposed to infected prey and would be more likely to consume infected prey due to higher metabolic requirements [7].

An interesting question is the extent to which vertical transmission could help reinforce the observed patterns of specificity. Currently, proof of vertical transmission exists for species of Halocercus [5-7] and Stenurus arctomarinus
[8]. Evidence of $H$. delphini being capable of vertical transmission in striped dolphins from the Mediterranean has been published previously from part of this same population [7], and this study also provides new evidence to that effect, with the finding of $H$. delphini in a Risso's dolphin neonate $(n=8)$. Stenurus globicephalae $(n=1)$ was also found in the same individual. This is the first record of vertical transmission of $H$. delphini in a Risso's dolphin, and also the first record of S. globicephalae being vertically transmitted. The means of this mode of transmission are still unclear, as there are three proposed non-exclusive mechanisms: inhalation of infected spray (i.e., aerosol), consumption of infected milk (i.e., lactogenic transmission) or transplacental infection $[5,69,70]$.

The fact that the neonatal Risso's dolphin harboured two species of lungworm could mean that both were transmitted the same way, or equally, it could mean that each species was transmitted via a different route. Unfortunately, there is no definitive proof for any of the proposed mechanisms, or for their relative role in vertical transmission. Considering the absence of lungworms in neonates in comparison to the frequency of infection of weaned individuals of the other three cetaceans, it is likely that horizontal transmission plays a more important role than vertical transmission in the initial infections of the hosts. However, it is difficult to assess the relative importance of vertical versus horizontal transmission in the life cycle of pseudaliids due to the lack of quantitative data in neonates, which are typically under-represented in samples of dolphins used for parasitological analysis.

\section{Conclusion}

In conclusion, this is the first study in which a quantitative assessment of host-lungworm specificity has been attempted in a local community of cetaceans. Two new host records are reported for $H$. delphini and S. ovatus. Available data suggest that phylogenetic specificity is a key driver of host-parasite associations: Halocercus delphini exhibits a preference for striped dolphins and common dolphins, and these are its preferred hosts in a global context, whereas Stenurus ovatus and S. globicephalae similarly demonstrate obvious host preference for the bottlenose dolphin and the long-finned pilot whale, respectively. However, infection patterns also suggest that a restricted level of colonization by parasites may also occur in other hosts via a shared diet. Due to the opportunistic nature of our research, we were unable to assess the relative roles of horizontal and vertical transmission of lungworms in the host species; however, we have provided new insights into the contributions and constraints of each in determining lungworm infection patterns in their cetacean hosts. 


\section{Abbreviations}

ITS2: Second internal transcribed spacer; ML: Maximum likelihood; BI: Bayesian inference; PS: Pairwise percent similarity index.

\section{Supplementary Information}

The online version contains supplementary material available at https://doi. org/10.1186/s13071-021-04629-1.

\section{Additional file 1: Table S1. Uncorrected pairwise distances between} samples of the lungworm Halocercus delphini collected from different host species calculated with MEGA7. Dashes represent null values and repeat values.

Additional file 2: Table S2. Frequency of occurrence of prey taxa shared between 5 odontocete species from the western Mediterranean. 'No. of prey taxa' refers to the total number of prey taxa identified up to genus level, and 'No. of shared prey taxa', the number of taxa that are shared with any of the other species. Data obtained from Blanco et al. ([34, 35], unpub. data), Santos et al. [37] and Aznar et al. [36]

Additional file 3: Table S3. Published field surveys that provide quantitative data on the lungworm species detected in the present study.

Additional file 4: Table S4. Values of prevalence (\%) for the three lungworm species found in this study in previous field surveys involving $\geq 3$ host species. Hyphens indicate that the host species was analyzed but the lungworm species was not found. Numbers in parentheses indicate sample sizes. Abbreviations: Ref., Reference; Dd, Delphinus delphis; Fa, Feresa attenuata; Gg, Grampus griseus; Gm, Globicephala melas; Gma, Globicephala macrorhynchus; La, Lagenorhynchus albirostris; Lea, Leucopleurus acutus; Lh, Lagenodelphis hosei; Oo, Orcinus orca; Pe, Peponocephala electra; Sa, Stenella attenuata; Sb, Steno bredanensis; Sc, Stenella coeruleoalba; Sf, Stenella frontalis; SI, Stenella longirostris; So, Sagmatias obliquidens; Sob, Sagmatias obscurus; Tt, Tursiops truncatus.

\section{Acknowledgements}

We greatly appreciate the assistance of our colleagues from the Marine Zoology Unit, University of Valencia, with stranded dolphins. We also thank the undergraduate students that helped dissect some of the lungs used in this study.

\section{Authors' contributions}

All authors contributed to the study conception and design. Material preparation and data collection were performed by RP and CR-R. Analyses were conducted by FA, MF and RP. The first draft of the manuscript was written by RP and FA, and all authors commented on previous versions of the manuscript. All authors read and approved the final manuscript.

\section{Funding}

Our study was made possible through support from the Servicio de Vida Silvestre, Conselleria de Agricultura, Medio Ambiente, Cambio Climático y Desarrollo Rural, and projects CGL/2012/39545 (Ministry of Economy and Competitiveness, Spain), and PROMETEO II/2015/018 (Generalitat Valenciana, Spain). RP benefitted from a scholarship by the Programa Santiago Grisolia de la Conselleria d'Educació, Investigació, Cultura i Esport (GrisoliaP-2017-093), CPI-17-214 (Generalitat Valenciana, Spain).

\section{Availability of data and materials}

Data used in analyses are available in the tables and supplementary files. ITS2 sequences obtained in this study have been uploaded to GenBank, and their accession numbers are available in Table 1.

\section{Ethics approval and consent to participate}

Not applicable.

\section{Consent for publication}

Not applicable.

\section{Competing interests}

The authors declare that they have no competing interests.

Received: 9 December 2020 Accepted: 6 February 2021

Published online: 12 April 2021

\section{References}

1. Measures LN. Lungworms of marine mammals. In: Samuel W, Pybus M, Kocan A, editors. Parasitic diseases of wild mammals. 2nd ed. Ames, lowa: lowa State Press; 2001. p. 279-300.

2. Fraija-Fernández N, Fernández M, Raga JA, Aznar FJ. Helminth diversity of cetaceans: an update. In: Kovacs A, Nagy P, editors. Advances in marine biology. New York: Nova Science Publishers, Inc; 2016. p. 29-100.

3. Anderson RC. Nematode parasites of vertebrates: their development and transmission. 2nd ed. Wallingford: CABI Publishing; 2000.

4. Lehnert K, Samson-Himmelstjerna G, Schaudien D, Bleidorn C, Wohlsein P, Siebert U. Transmission of lungworms of harbour porpoises and harbour seals: molecular tools determine potential vertebrate intermediate hosts. Int J Parasitol. 2010;40:845-53.

5. Fauquier DA, Kinsel MJ, Dailey MD, Sutton GE, Stolen MK, Wells RS, Gulland FMD. Prevalence and pathology of lungworm infection in bottlenose dolphins Tursiops truncatus from southwest Florida. Dis Aquat Org. 2009;88:85-90

6. Reckendorf A, Ludes-Wehrmeister E, Wohlsein P, Tiedemann R, Siebert U, Lehnert K. First record of Halocercus sp. (Pseudaliidae) lungworm infections in two stranded neonatal orcas (Orcinus orca). Parasitology. 2018;145(12):1553-7.

7. Pool R, Chandradeva N, Gkafas G, Raga JA, Fernández M, Aznar FJ. Transmission and predictors of burden of lungworms of the striped dolphin (Stenella coeruleoalba) in the Western Mediterranean. JWildl Dis. 2020;56(1):186-91.

8. Burek-Huntington KA, Dushane JL, Goertz CE, Romero CH, Raverty SA. Morbidity and mortality in stranded Cook Inlet beluga whales Delphinapterus leucas. Dis Aquat Org. 2015;114(1):45-60.

9. Terracciano G, Fichi G, Comentale A, Ricci E, Mancusi C, Perrucci S. Dolphins Stranded along the Tuscan Coastline (Central Italy) of the "Pelagos Sanctuary": a parasitological investigation. Pathogens. 2020;9(8):612.

10. Gibson DI, Harris EA, Bray RA, Jepson PD, Kuiken T, Baker JR, Simpson VR. A survey of the helminth parasites of cetaceans stranded on the coast of England and Wales during the period 1990-1994. J Zool. 1998;244(4):563-74.

11. Oliveira JB, Morales JA, González-Barrientos RC, Hernández-Gamboa J, Hernández-Mora G. Parasites of cetaceans stranded on the Pacific coast of Costa Rica. Vet Parasitol. 2011;182(2-4):319-28.

12. Euzet $L$, Combes $C$. Les problemes de l'espèce chez les animaux parasites. Mém Soc Zool Fr. 1980;3:239-85.

13. Kuris AM, Goddard JH, Torchin ME, Murphy N, Gurney R, Lafferty KD. An experimental evaluation of host specificity: the role of encounter and compatibility filters for a rhizocephalan parasite of crabs. Int J Parasitol. 2007;37(5):539-45.

14. Lima LB, Bellay S, Giacomini HC, Isaac A, Lima-Junior DP. Influence of host diet and phylogeny on parasite sharing by fish in a diverse tropical floodplain. Parasitology. 2016;143(3):343-9.

15. Poulin R, Krasnov BR, Mouillot D. Host specificity in phylogenetic and geographic space. Trends Parasitol. 2011;27(8):355-61.

16. Mateu P, Nardi V, Fraija-Fernández N, Mattiucci S, de Sola LG, Raga JA, Fernández M, Aznar FJ. The role of lantern fish (Myctophidae) in the lifecycle of cetacean parasites from western Mediterranean waters. Deep Sea Res Part I Oceanogr Res Pap. 2015;95:115-21.

17. Geraci JR, Lounsbury VJ. Marine mammals ashore: a field guide for strandings. National Aquarium in Baltimore; 2005.

18. Delyamure SL. Helminthofauna of marine mammals (ecology and phylogeny). Moscow: Izdatel'stvo Akademii Nauk SSSR; 1955.

19. Blouin MS. Molecular prospecting for cryptic species of nematodes: mitochondrial DNA versus internal transcribed spacer. Int J Parasitol. 2002;32(5):527-31. https://doi.org/10.1016/S0020-7519(01)00357-5. 
20. Pool R, Fernández M, Chandradeva N, Raga JA, Aznar FJ. The taxonomic status of Skrjabinalius guevarai Gallego \& Selva, 1979 (Nematoda: Pseudaliidae) and the synonymy of Skrjabinalius Delyamure, 1942 and Halocercus Baylis \& Daubney, 1925. Syst Parasitol. 2020;12:1-3.

21. Katoh K, Standley DM. MAFFT multiple sequence alignment software version 7: improvements in performance and usability. Mol Biol Evol. 2013;30:772-80.

22. Capella-Gutiérrez S, Silla-Martínez JM, Gabaldón T. trimAl: a tool for automated alignment trimming in large-scale phylogenetic analyses. Bioinformatics. 2009;25(15):1972-3.

23. Guindon S, Gascuel O. A simple, fast, and accurate algorithm to estimate large phylogenies by maximum likelihood. Syst Biol. 2003;52(5):696-704.

24. Darriba D, Taboada GL, Doallo R, Posada D. jModelTest 2: more models, new heuristics and parallel computing. Nat Methods. 2012;9(8):772.

25. Kumar S, Stecher G, Li M, Knyaz C, Tamura K. MEGA X: molecular evolutionary genetics analysis across computing platforms. Mol Biol Evol. 2018;35(6):1547-9.

26. Huelsenbeck JP, Ronquist F. MRBAYES: Bayesian inference of phylogenetic trees. Bioinformatics. 2001;17(8):754-5.

27. Rambaut A. (2010). FigTree v1.3.1. http://tree.bio.ed.ac.uk/software/figtr ee/. Accessed on 1 October 2019.

28. Reiczigel J, Marozzi M, Fábián I, Rózsa L. Biostatistics for parasitologists-a primer to quantitative parasitology. Trends Parasitol. 2019;35(4):277-81.

29. Read AJ, Wells RS, Hohn AA, Scott MD. Patterns of growth in wild bottlenose dolphins, Tursiops truncatus. J Zool. 1993;231(1):107-23.

30. Struntz DJ, Mclellan WA, Dillaman RM, Blum JE, Kucklick JR, Pabst DA. Blubber development in bottlenose dolphins (Tursiops truncatus). J Morphol. 2004;259(1):7-20.

31. Raduán A, Blanco C, Fernández M, Raga JA. Some aspects of the life history of the Risso's dolphins Grampus griseus (Cuvier, 1812) in the western Mediterranean Sea. In: Proceedings of the Annual Conference of the European Cetacean Society 2007 (Vol. 21); 2007.

32. Bloch D, Desportes G, Harvey P, Lockyer C, Mikkelsen B. Life history of Risso's dolphin (Grampus griseus)(G. Cuvier, 1812) in the Faroe Islands. Aquat Mamm. 2012;38(3):250-66.

33. Westgate AJ, Read AJ. Reproduction in short-beaked common dolphins (Delphinus delphis) from the western North Atlantic. Mar Biol. 2007:150(5):1011-24.

34. Blanco C, Salomón O, Raga JA. Diet of the bottlenose dolphin (Tursiops truncatus) in the western Mediterranean Sea. J Mar Biol Assoc UK. 2001;2001 (81):1053-8.

35. Blanco C, Raduán MA, Raga JA. (2006) Diet of Risso's dolphin (Grampus griseus) in the western Mediterranean Sea. Sci Mar. 2006;70:407-11.

36. Aznar FJ, Miguel-Lozano R, Ruiz B, Bosch de Castro A, Raga JA, Blanco C Long-term changes (1990-2012) in the diet of striped dolphins Stenella coeruleoalba from the western Mediterranean. Mar Ecol Prog Ser. 2017; 568: $231-247$

37. Santos MB, Monteiro SS, Vingada JV, Ferreira M, López A, Martínez Cedeira $J A$, Reid RJ, Brownlow A, Pierce GJ. Patterns and trends in the diet of longfinned pilot whales (Globicephala melas) in the northeast Atlantic. Mar Mamm Sci. 2014;30(1):1-19.

38. Rosenberg MS, Anderson CD. PASSaGE: pattern analysis, spatial statistics and geographic exegesis. Version 2. Methods Ecol Evol. 2011;2(3):229-32.

39. Morand S. Life-history traits in parasitic nematodes: a comparative approach for the search of invariants. Funct Ecol. 1996;10(2):210-8.

40. McGowen MR, Tsagkogeorga G, Álvarez-Carretero S, dos Reis M, Struebig M, Deaville R, Jepson PD, Jarman S, Polanowski A, Morin PA, Rossiter SJ. Phylogenomic resolution of the cetacean tree of life using target sequence capture. Syst Biol. 2020;69(3):479-501.

41. Rózsa L, Reiczigel J, Majoros G. Quantifying parasites in samples of hosts. J Parasitol. 2000;86(2):228-32.

42. R Core Team (2017). R: a language and environment for statistical computing. https://www.R-project.org/. Accessed 30 November 2017.

43. Zam SG, Caldwell DK, Caldwell MC. Some endoparasites from small odontocete cetaceans collected in Florida and Georgia. Cetology. 1971:2:1-11.

44. Forrester DJ, Odell DK, Thompson NP, White JR. Morphometrics, parasites, and chlorinated hydrocarbon residues of pygmy killer whales from Florida. J Mammal. 1980;1980(61):356-60.
45. Morales-Vela B, Olivera-Gomez LD. Varamiento de calderones Globicephala macrorhynchus (Cetacea: Delphinidae) en la Isla de Cozumel, Quintana Roo, México. An Inst Biol Univ Nac Auton Mex Ser Zool. 1993;64:177-80.

46. Raga JA, Balbuena JA. Parasites of the long-finned pilot whale, Globicephala melas (Traill, 1809). European waters. In: Donovan GP, Lockyer $\mathrm{CH}$, Martin AR, editors. Biology of Northern Hemisphere pilot whales. Cambridge, UK: International Whaling Commission; 1993. p. 391-406.

47. Schick L, IJsseldijk LL, Grilo ML, Lakemeyer J, Lehnert K, Wohlsein P, Ewers C, Prenger-Berninghoff E, Baumgärtner W, Gröne A, Kik MJ. Pathological findings in white-beaked dolphins (Lagenorhynchus albirostris) and Atlantic white-sided dolphins (Lagenorhynchus acutus) from the South-Eastern North Sea. Front Vet Sci. 2020;7:1-17.

48. Rogan E, Baker JR, Jepson PD, Berrow S, Kiely O. A mass stranding of white-sided dolphins (Lagenorhynchus acutus) in Ireland: biological and pathological studies. J Zool. 1997;242(2):217-27.

49. Zylber MI, Failla G, Le Bas A. Stenurus globicephalae Baylis et Daubney, 1925 (Nematoda: Pseudaliidae) from a false killer whale, Pseudorca crassidens (Cetacea: Delphinidae), stranded on the coast of Uruguay. Mem Inst Oswaldo Cruz. 2002;97(2):221-5.

50. Dailey MD, Perrin WF. Helminth parasites of porpoises of the genus Stenella in the eastern tropical Pacific, with descriptions of two new species: Mastigonema stenellae gen. et. sp. n. (Nematoda: Spiruroidea) and Zalophotrema pacificum sp. n. (Trematoda: Digenea). Fish Bull. 1973;71:455-71.

51. Cowan D, Walker W. Disease factors in Stenella attenuata and Stenella longirostris taken in the eastern tropical Pacific yellowfin tuna purse sine fishery. Southwest Fisheries Science Center, Santa Cruz, California: National Marine Fisheries Service, NOAA; 1979. Administrative Report No. LJ-79-32C.

52. Troncone A, Zizzo N, Colella G, Perillo A, Manfredi MT. Parassitosi dei delfini Incidenza di infestazioni parassitarie in delfini "spiaggiati." Obiettivi doc vet. 1994;12:39-42.

53. McColl KA, Obendorf DI. Helminth parasites and associated pathology in stranded Fraser's dolphins, Lagenodelphis hosei (Fraser, 1956). Aquat Mamm. 1982;9(2):30-4.

54. Tomo I, Kemper CM, Lavery TJ. Eighteen-year study of South Australian dolphins shows variation in lung nematodes by season, year, age class, and location. J Wildl Dis. 2010;46:488-98.

55. Cowan I. MCT. 1988. The marine mammals of British Columbia, their status and distribution. In: Fox RJ, editor. The wildlife of northern British Columbia_-past, present and future. Smithers, BC: Spatsizi Association for Biological Research; 1987. p. 95-104.

56. McManus TJ, Wapstra JE, Guiler ER, Munday BL, Obendorf DL. Cetacean strandings in Tasmania from February 1978 to May 1983. Pap Proc R Soc Tasmania. 1984;118:117-35

57. Geraci JR. The enigma of marine mammal strandings. Oceanus. 1978;1978(21):38-47.

58. Cannon LR. Some aspects of the biology of Peponocephala electra (Cetacea: Delphinidae) II. Parasites. Mar Freshw Res. 1977;28(6):717-22.

59. Aguilar-Aguilar R, Delgado-Estrella A, Moreno-Navarrete R. New host report for nematodes in a stranded short-snouted spinner dolphin Stenella clymene (Cetacea: Delphinidae) from the Mexican Caribbean coast. Helminthologia. 2010;47(2):136-8.

60. Birkun A. Natural mortality factors affecting cetaceans in the Black Sea. In: Notarbartolo di Sciara G, editor. Cetaceans of the Mediterranean and Black Seas: state of knowledge and conservation strategies. A report to the ACCOBAMS Secretariat, Monaco, February 2002. Monaco: ACCOBAMS; 2002.

61. Abollo E, Lopez A, Gestal C, Benavente P, Pascual S. Macroparasites in cetaceans stranded on the northwestern Spanish Atlantic coast. Dis Aquat Org. 1998:32(3):227-31.

62. Cremer MJ, Holz AC, Sartori CM, Schulze B, Paitach RL, Simões-Lopes PC. Behavior and ecology of endangered species living together: Long-term monitoring of resident sympatric dolphin populations. In Rossi-Santos M, Finkl C, editors. Advances in marine vertebrate research in Latin America. Coastal Research Library vol. 22 Cham: Springer; 2018. p. 477-508.

63. Dailey MD, Otto KA. Parasites as biological indicator of the distributions and diets of marine mammals common to the eastern Pacific. Tiburon, 
California: Southwest Fisheries Center; 1982. Administrative Report LJ-82- 13CC.

64. Lehnert K, Randhawa H, Poulin R. Metazoan parasites from odontocetes off New Zealand: new records. Parasitol Res. 2017;116(10):2861-8.

65. Mignucci-Giannoni AA, Hoberg EP, Siegel-Causey D, Williams EH Jr. Metazoan parasites and other symbionts of cetaceans in the Caribbean. J Parasitol. 1998;84(5):939-46.

66. Aytemiz I, Dede A, Danyer E, Tonay AM. Morphological identification of parasites found in the stomach contents of bycaught striped dolphins (Stenella coeruleoalba) from Turkish Eastern Mediterranean Sea coast. J Black Sea/Mediterr. 2012;18:238-45.

67. Carreno RA, Caporossi D, Beade MS, Marull CA, Uhart MM, Markwardt DD, Nadler SA. Discovery of an undescribed protostrongylid nematode from the endangered pampas deer (Ozotoceros bezoarticus celer) in Argentina. J Wildl Dis. 2012;48(3):724-31.

68. Eamsobhana P, Lim PE, Yong HS. Phylogenetics and systematics of Angiostrongylus lungworms and related taxa (Nematoda : Metastrongyloidea) inferred from the nuclear small subunit (SSU) ribosomal DNA sequences. J Helminthol. 2015;89:317-25.

69. Caldwell MC, Caldwell DK, Zam SG. (1968) 'Occurrence of the Lungworm (Halocercus sp.) in Atlantic Bottlenose Dolphins (Tursiops truncatus) as a Husbandry Problem. In Caldwell DK, Caldwell MC, editors. Proceedings of the second symposium on diseases and husbandry of aquatic mammals. St. Augustine, Florida: Marineland of Florida; 1968. p. 11-15.

70. Dailey M, Walsh M, Odell D, Campbell T. Evidence of prenatal infection in the bottlenose dolphin (Tursiops truncatus) with the lungworm Halocercus lagenorhynchi (Nematoda: Pseudaliidae). J Wildl Dis. 1991;27(1):164-5.

\section{Publisher's Note}

Springer Nature remains neutral with regard to jurisdictional claims in published maps and institutional affiliations.
Ready to submit your research? Choose BMC and benefit from:

- fast, convenient online submission

- thorough peer review by experienced researchers in your field

- rapid publication on acceptance

- support for research data, including large and complex data types

- gold Open Access which fosters wider collaboration and increased citations

- maximum visibility for your research: over $100 \mathrm{M}$ website views per year

At BMC, research is always in progress.

Learn more biomedcentral.com/submissions 